Carta ao Editor / Letter to Editor

\section{Identificação de Hb AB2 em dois caucasianos da região Amazônica por procedimentos eletroforéticos e cromatográficos}

\section{Identification of $\mathrm{Hb}$ AB2 in two Caucasian of the Amazonian region by electrophoresis and chromatography}

\author{
Felipe R. Torres ${ }^{1}$ \\ Luciana S. Ondei ${ }^{1}$ \\ Paula J. A. Zamaro ${ }^{1}$ \\ Ricardo Machado ${ }^{2}$ \\ Claudia R.Bonini-Domingos ${ }^{l}$
}

\footnotetext{
${ }^{I}$ Universidade Estadual Paulista (Unesp) - Instituto de Biociências, Letras e Ciências Exatas - Depto. de Biologia - Laboratório de Hemoglobinas e Genética das Doenças Hematológicas - LHGDH. ${ }^{2}$ Faculdade de Medicina de São José do Rio Preto (Famerp) Depto. de Doenças Infecciosas, Dermatológicas e Parasitárias Centro de Investigação de Microorganismos - CIM.
}

Trabalho realizado no $L H G D H$ - Ibilce - Unesp, São José do Rio Preto-SP.

\section{Sr. Editor:}

A variante de globina delta $(\delta)$ chamada $\mathrm{Hb} \mathrm{B} 2$, originalmente identificada como $\mathrm{Hb} \mathrm{A}$, resulta da substituição de uma glicina por uma arginina na posição 16 da cadeia $\delta .{ }^{1}$ É a variante de cadeia $\delta$ mais freqüente no mundo. Tem sido descrita na África e em populações de descendência africana e encontrada em combinação com $\mathrm{Hb} \mathrm{S}, \mathrm{Hb} \mathrm{C}$, beta talassemia, e em homozigose. ${ }^{2}$ Sua freqüência varia de $1 \%$ a $3 \%$ em negros americanos, acima de $9 \%$ em negros africanos e tem rara distribuição em caucasianos, o que inicialmente levou pesquisadores a assumir a teoria de que a variante era africanoespecífica. ${ }^{1}$ A ausência de $\mathrm{Hb}$ B2 em algumas regiões africanas sugere que esta variante é específica de negros e não necessariamente de africanos. ${ }^{1}$ Bennani et $\mathrm{al}^{3}$ demonstraram que o gene $\delta$-globina mutado está associado a um único haplótipo, e sua origem poderia ser africana, mas mutações recorrentes não poderiam ser descartadas para explicar esta hipótese devido a ligação entre o agrupamento de genes $\beta$ com a Hb B2 ser um dos haplótipos mais freqüentes em toda população africana.

O gene da $\delta$-globina está localizado próximo ao gene da $\beta$-globina no braço curto do cromossomo 11 , e devido a esta proximidade, existe uma probabilidade baixa de ocorrer recombinação entre esses dois genes, e uma alta probabilidade dos genes serem herdados juntos, levando à ocorrência de variantes estruturais de cadeia $\delta$ e $\beta$ em conjunto. ${ }^{4}$

Neste trabalho relatamos o aparecimento de $\mathrm{Hb}$ B2 em duas mulheres, com idades de 23 e 32 anos, ambas caucasóides, provenientes de uma amostra de 99 doadores de sangue do Acre e de 100 pacientes maláricos do Pará. Foram coletados $5 \mathrm{~mL}$ de sangue venoso em tubo contendo EDTA. As amostras foram estocadas sob refrigeração até a realização dos procedimentos laboratoriais de identificação de hemoglobinas. As amostras foram colhidas após consentimento informado.

Em eletroforese $(\mathrm{pH} 8,5)$ em acetato de celulose, ${ }^{5}$ as amostras hemolisadas com saponina $1 \%$ e clorofórmio ${ }^{5}$ mostraram mobilidade normal para a $\mathrm{Hb} \mathrm{A} 2$ e uma fração adicional, mais próxima do pólo negativo, sugerindo uma variante de cadeia delta, devido à sua baixa concentração (Figura 1). Nas eletroforeses em $\mathrm{pH}$ ácido e neutro não foram observadas alterações no perfil das hemoglobinas, sugerindo que esta variante migre na mesma posição de $\mathrm{Hb} \mathrm{A}$.

Na amostra do Pará observou-se também a presença de $\mathrm{Hb} \mathrm{H}$, confirmada por testes citológicos e eletroforéticos específicos, conforme anteriormente descrito, ${ }^{5}$ caracterizando uma associação com alfa talassemia. Para os valores quantitativos de $\mathrm{Hb} \mathrm{A} 2, \mathrm{Hb} \mathrm{F}$ e perfil da variante de hemoglobina utilizou-se a cromatografia líquida de alta pressão (HPLC) de troca cationnica pelo sistema automatizado Variant I (Bio-Rad) com o uso do kit de diagnóstico " $\beta$ Thalassemia Short". ${ }^{6}$ Em ambas as amostras, os níveis de $\mathrm{Hb} \mathrm{A} 2$ foram de $1,8 \%$, inferiores ao mínimo esperado de 2,5\% (Figura 2 A-B). Os níveis diminuídos de $\mathrm{A} 2$ indicam uma menor produção de cadeias $\delta$ normais. O perfil cromatográfico evidenciou uma fração de

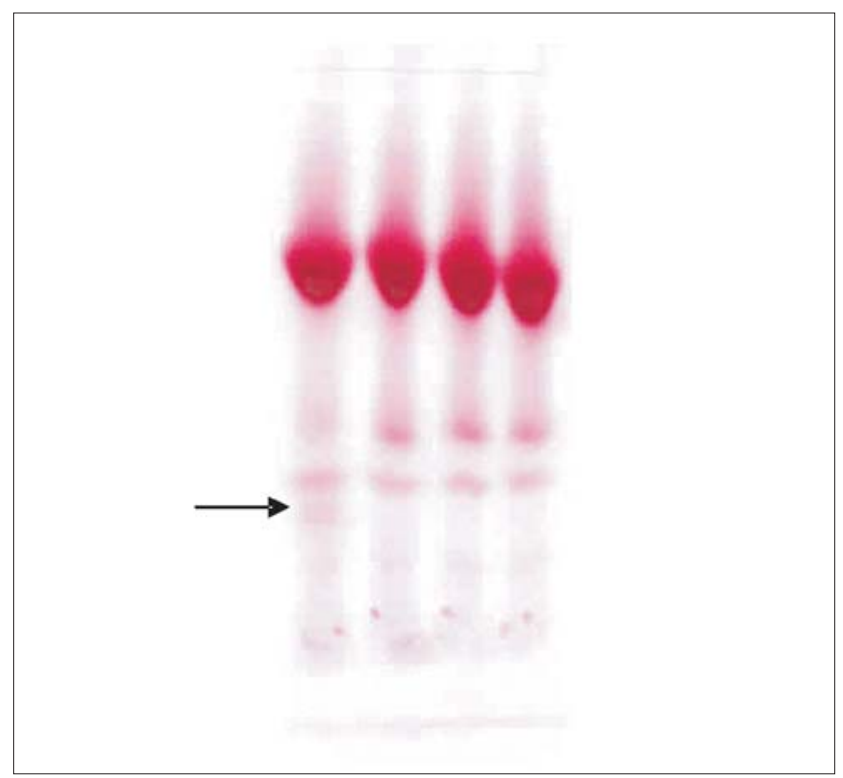

Figura 1. Eletroforese alcalina $(\mathrm{pH} \mathrm{8,5)} \mathrm{em} \mathrm{acetato} \mathrm{de} \mathrm{celulose.} \mathrm{A}$ seta indica a fração adicional sugestiva de Hb B2. 
A

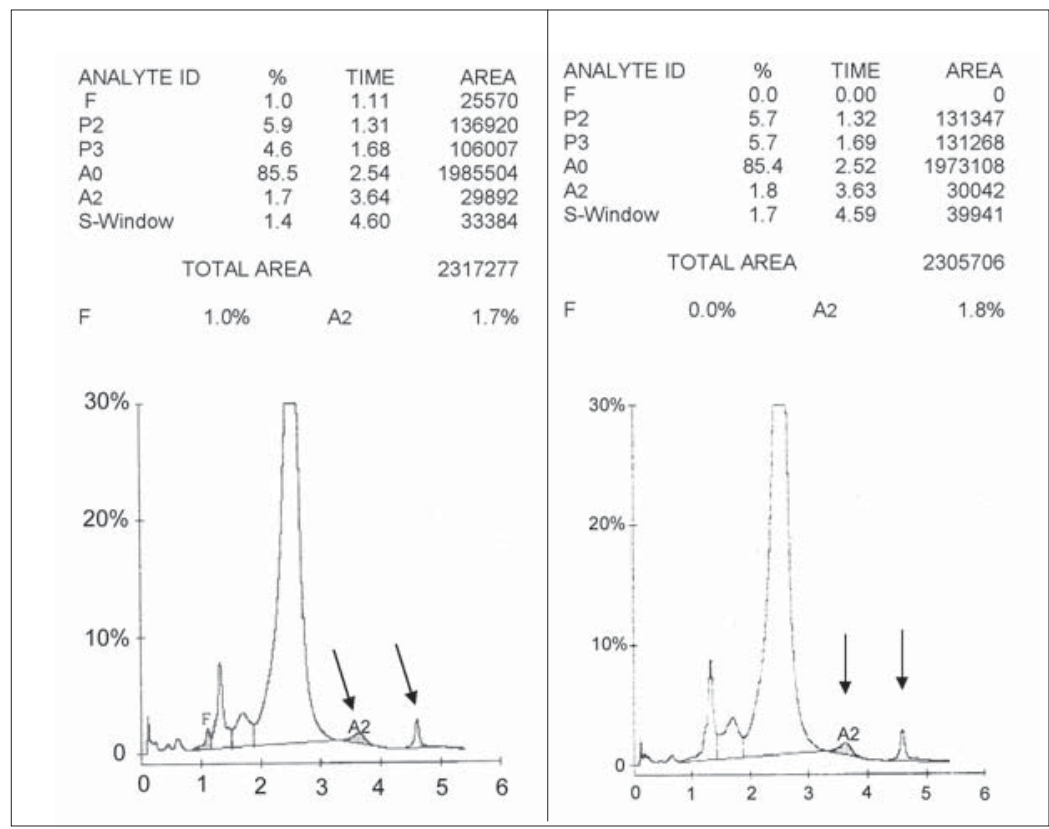

Figura 2. Perfil cromatográfico obtido pelo equipamento Variant (Bio-Rad) de HPLC em doadores do Pará (A) e Acre (B). As setas cheias indicam a fração de Hb A2 reduzida e as pontilhadas a fração de $\mathrm{Hb}$ B2.
Devido à sua baixa concentração $(1,4 \% \mathrm{e}$ $1,7 \%)$, em procedimentos eletroforéticos e cromatográficos a fração da variante B2 pode passar desapercebida e sua freqüência em grupos populacionais brasileiros estar subestimada. Com este relato de caso pretendemos chamar a atenção para a identificação desta variante no Brasil, pelos serviços de rastreamento e diagnóstico de hemoglobinas anormais, contribuindo para o conhecimento desse polimorfismo de $\mathrm{Hb}$ na população.

\section{Abstract}

Hemoglobin B2, variant of $\delta$ globin chain, presents an increased frequency in African and afrodescendant populations but is considered rare in Caucasians. It does not present physiopathology effects in heterozygosis and it has been spread around the world by the founder effect. In this paper we report on the identification of $\mathrm{Hb} \mathrm{B} 2$ in heterozygosis, by the association of electrophoretic and chromatography procedures, in two Caucasian women from Acre and Pará States, Brazil, which are endemic areas for Malaria.

Key words: $\delta$ globin variant; $H b$ B2; Hb A2 variant. baixa concentração $(1,4 \%$ e $1,7 \%)$ com tempo de retenção de 4,59 minutos e 4,60 minutos e distribuição gráfica compatível com a variante B2. As eletroforeses de cadeias globínicas em $\mathrm{pH}$ alcalino e ácido evidenciaram a presença da globina $\delta$ mutante.

As variantes de globina $\delta$ não estão associadas a manifestações fenotípicas e clínicas significativas, devido ao baixo nível de produção dessas cadeias na formação das moléculas de $\mathrm{Hb}$ dentro dos eritrócitos. ${ }^{4}$ As observações sobre a Hb B2 não evidenciam nenhuma explicação seletiva ou de proteção contra agentes ambientais para sua dispersão a partir de sua origem, provavelmente, africana. A alta incidência em algumas populações pode ser explicada por efeito do fundador, mas a dispersão provavelmente foi por deriva genética, principalmente pelo intenso fluxo de imigrantes africanos para outras partes do mundo. ${ }^{1,2,3}$

Nos dois casos relatados neste trabalho, os indivíduos são caucasóides, grupo étnico em que a freqüência de Hb B2 é considerada rara. ${ }^{4} \mathrm{~A}$ incidência de dois indivíduos em 200 amostras com a variante $\mathrm{Hb}$ B2 é de 1\%, relativamente baixa quando comparada com outras variantes de hemoglobinas no Brasil, mas suficiente para a caracterização do polimorfismo no grupo avaliado. Considerando-se as condições de formação da população brasileira, principalmente a alta miscigenação entre os diferentes grupos étnicos, incluindo os africanos, pode-se explicar o aparecimento de $\mathrm{Hb}$ B2 em dois indivíduos caucasianos, destacando que, em ambos os casos, a variante aparece em heterozigose e, apenas em um, observou-se associação com outra hemoglobina assintomática, a alfa talassemia.

\section{Referências Bibliográficas}

1. Spurdle AB, Krause A, Ramsay M, Jenkins T. The high frequency of the B2 variant in the Herero population: a founder efect? Hemoglobin 1994; 18: 317-234.

2. Schiliro G, Russo-Mancuso G, Dibenedetto SP, et al. Six rare hemoglobin variants found in Sicily. Hemoglobin 1991;15(5):432-7.

3. Bannani M, Mombo LE, Chaventre A, et al. Origin of $\mathrm{Hb}$ A2' $(\mathrm{Hb}$ B2) [d16 (A13) Gly®Arg (GGC®CGC). Hemoglobin 2003;27(2): 105-10.

4. Honig GR, Adams JG. Human Hemoglobin Genetics. Springer-Verlag Wien New York 1986.

5. Domingos ACB, Viana-Baracioli LMS, Bonini-Domingos CR. Identificação de variantes de hemoglobinas em doadores de sangue. Rev Bras Hematol e Hemoter 2004;26(1):57-9.

6. Souza WC, Torres FR, Salvador AR, et al. Avaliação de $\mathrm{Hb}$ A2 e Hb $\mathrm{F}$ em doadores de sangue de região malarígena da Amazônia Oriental brasileira por HPLC. Rev Bras Hematol e Hemoter 2003; 25 (4):263-6.

Avaliação: Editor e dois revisores externos.

Conflito de interesse: assessor científico da Bio-Rad para a linha de Biologia Molecular (Life Science) desde 2001

Recebido: 25/04/05

Aceito após modificações: 18/05/05

Correspondência para: Felipe Rafael Torres

Laboratório de Hemoglobinas e Genética das Doenças

Hematológicas - LHGDH. - Ibilce-Unesp

Rua Cristóvão Colombo, 2265

São José do Rio Preto, SP.

E-mail: frtorres@zipmail.com.br 